\title{
Review
}

\section{Neurotrophins: the biological paradox of survival factors eliciting apoptosis}

\author{
Patrizia Casaccia-Bonnefil ${ }^{1,2}$, Haeyoung Kong ${ }^{1}$ and \\ Moses V. Chao ${ }^{1}$ \\ ${ }^{1}$ Molecular Neurobiology Program, Skirball Institute, 540 First Avenue, New \\ York, USA 10016 \\ 2 Coresponding author: Patrizia Casaccia-Bonnefil: tel 212-263-0722; \\ fax 212-263-8214; e-mail: pcasacci@saturn.med.nyu.edu
}

Received 25.8.97; revised 8.1.98; accepted 9.2.98

Edited by G. Melino

\begin{abstract}
Neurotrophins are target-derived soluble polypeptides required for neuronal survival. Binding of neurotrophins to Trk receptor tyrosine kinases initiate signaling cascades that promote cell survival and differentiation. All family members bind to another receptor $\left(\mathrm{p} 75^{\mathrm{NTR}}\right)$, which belongs to the tumor necrosis factor superfamily. Hence, nerve growth factor (NGF) and related trophic factors are unique in that two separate receptor types are utilized. Although the biological function of p $75^{\mathrm{NTR}}$ has been elusive, it has been suggested to mediate apoptosis of developing neurons in the absence of Trk receptors. This presents a tantalizing paradigm, in which lifedeath decisions of cells are dependent upon the expression and action of two different receptors with distinctive signaling mechanisms. In the presence of TrkA receptors, p75 can participate in the formation of high affinity binding sites and enhanced NGF responsiveness leading to a survival signal. In the absence of TrkA receptors, p75 can generate, in only specific cell populations, a death signal. Here we discuss the unique features and implications of this unusual signal transduction system.
\end{abstract}

Keywords: brain; ceramide; tumor necrosis factor receptors; central nervous system

Abbreviations: NGF, nerve growth factor; BDNF, brain derived neurotrophic factor; NT, neurotrophin; TNF, tumor necrosis factor; TrK, tyrosine kinase receptor; MAP, mitogen activated protein kinase; JNK, c-jun; $\mathrm{N}$ terminal kinase

\section{Introduction}

Neurotrophic factors, exemplified by NGF, are peptides synthesized by target tissues that promote the survival of afferent neurons. Competition among neurons for limiting amounts of neurotrophin molecules produced by target cells has been established as a principal mechanism to account for cell survival during development. An important prediction from this theory is that the efficacy of neurotrophin action will depend upon the availability of trophic factors and activation of their receptors in responsive cell populations.

Recent evidence indicates that neurotrophins use a tworeceptor system to dictate signaling pathways leading to either cell survival or suicide. The TrkA, TrkB, and TrkC tyrosine kinases serve as the receptors for NGF, BDNF, and NT-3, respectively, and $\operatorname{trk} A$ and $\operatorname{trk} B$ may also function as receptors for NT-3 and NT-4/5 (Chao, 1992). In addition, the p75 receptor can serve as a receptor for NGF, BDNF, NT-3 and NT-4, and exhibits slightly different binding characteristics for each factor (Figure 1). This review article will focus upon different receptor mechanisms that lead to alternative signaling outcomes influencing cell viability. This topic has been a continuing source of controversy and confusion due to the existence of two completely different classes of receptors for the neurotrophins.

\section{An outside family member?}

The 75 receptor is the founding member of the TNF receptor superfamily (Smith et al, 1994). This group of receptors is composed of type I membrane proteins (Figure 1), such as the TNFR I and II, Fas-CD95, the lymphoid cell-specific receptor CD30, CD40 and CD27, and the most recently discovered members DR-3, DR-4 and GITR (Brojatsch et al, 1996; Chinnaiyan et al, 1996; Montgomery et al, 1996; Pan et al 1997). All of these transmembrane proteins share in their extracellular domains a common cysteine motif that spans 40 amino acids and is repeated two to six times. In addition, several members contain a region of weak homology in the intracellular portion, designated the death domain (Figure 1). The death domain should be more appropriately regarded as a protein-protein interaction domain since many unrelated proteins, such as ankyrin and the unc-5/netrin receptor, possess this motif (Feinstein et al, 1995; Hofmann and Tschopp, 1995) and are not associated with apoptosis.

Interestingly, all the known ligands for the TNF receptor superfamily are type II transmembrane proteins with a short $\mathrm{N}$-terminal cytoplasmic tail and a C-terminal extracellular domain. Each ligand in the family acts as a trimer, with the exception of the neurotrophins, which exist as homodimers of identical subunits held strongly together by hydrophobic forces. The active form of NGF is a 118 amino acid protein which is produced from dibasic proteolytic cleavages (Greene and Shooter, 1980). In addition, neurotrophins are secreted proteins, and therefore differ significantly from the TNF family of ligands, which are expressed as transmembrane proteins. 
These differences raise the intriguing question of whether a TNF type of ligand exists for the p75 receptor. There is evidence in the mollusk Lymnaea stagnalis that p75 can bind to a novel ligand, called CRNF (cysteine-rich neurotrophic factor), which is characterized with cysteinerich motifs. However CRNF is unrelated to the NGF or TNF family members (Fainzilber et al, 1996). Treatment of Lymnaea neurons with CRNF resulted in process extension, suggesting that CRNF may be interacting with a p75 related receptor. However, Lymnaea homologs of $\mathrm{p} 75$ have not been identified, nor has a mammalian counterpart of CRNF been isolated. This ligand-receptor system may represent a primitive form of neurotrophin-receptor interaction, or an evolutionary dead end. Therefore the existence of a TNF-like ligand for p75 remains an open question.

\section{Mechanisms of p75 action}

The functions of p75 have been subject of considerable debate and interest. Proposed roles have ranged from a presentation receptor to a G protein-coupled receptor; from a receptor specialized for concentrating neurotrophins to a cell death receptor (Bredesen and Rabizadeh, 1997; Carter and Lewin, 1997; Chao and Hempstead, 1995). Most of the available information regarding the role of p75 comes from studies conducted in the presence of the TrkA NGF receptor. The potential biological actions of the p75 receptor may be best explained by considering three paradigmatical situations:

\section{1. p75 as an enhancer of cell survival and differentiation}

For neurotrophin-responsive neuronal populations, p75 and Trk are frequently co-expressed. The p75 receptor, when coexpressed with TrkA, provides a positive modulatory influence on TrkA function (Barker and Shooter, 1994; Verdi et al,
1994). Responsiveness to NGF and the ability to form high affinity sites are dependent on the relative levels of $p 75$ and TrkA receptors. Two models have been proposed to account for how p75 can modulate Trk receptor function. The first is a ligand passing mechanism, which predicts that the high affinity state is the result of ligand presentation by $p 75$ to the TrkA receptor (Barker and Shooter, 1994). The second model predicts that p75 and TrkA are capable of a ligandindependent association, which produces a high affinity binding interaction. Such a mechanism would predict that conformational changes in a receptor complex facilitate ligand binding. This idea is supported by ligand-independent clustering and interactions between the two receptors observed in co-patching and biophysical measurements (Ross et al, 1996).

In neuronal cell lines that express both TrkA and p75 receptors, TrkA autophosphorylation is enhanced, leading to a faster differentiative response, as assayed by more rapid growth arrest and neuronal maturation (Verdi et al, 1994). In the absence of p75, there are selective losses in sensory and sympathetic innervation (Davies et al, 1993; Lee et al, 1992, 1994a) consistent with, but not as severe as phenotypes exhibited by NGF, BDNF, NT-3 and trkA, trkB and trkC null mice (Snider, 1994).

Cell survival is also enhanced by a higher ratio of p75 to Trk receptors. Sensory neurons from $\mathrm{p} 75^{-1-}$ embryonic sensory trigeminal neurons and neonatal sympathetic neurons show a nearly fourfold greater requirement for NGF for cell survival compared to wild-type neurons (Davies et al, 1993; Lee et al, 1994b). Although these neurons are fully capable of responding to NGF through the trkA receptor, in the absence of p75 they do so with a significantly lower sensitivity. Correspondingly, sympathetic neurons from neonatal p75-null mice required higher concentrations of NGF to survive than neurons from normal mice at earlier developmental stages (Lee et al,

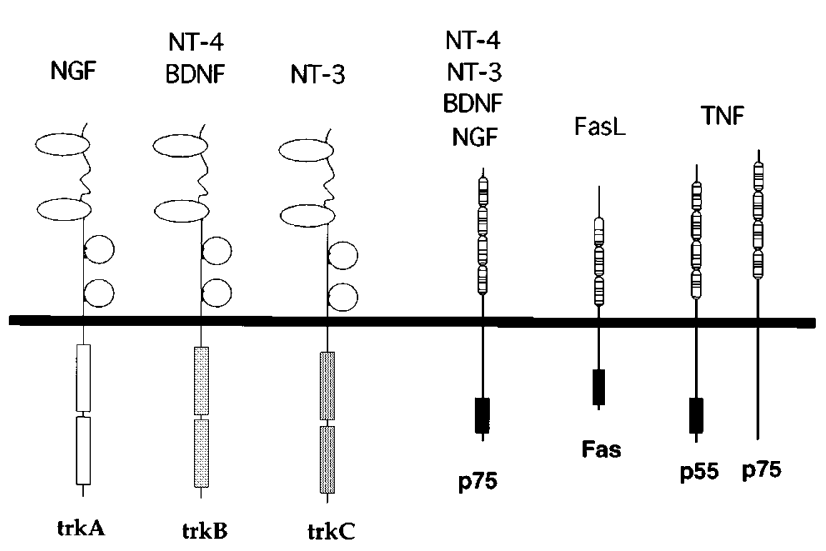

Figure 1 Receptors for neurotrophins and tumor necrosis factor family members. A schematic representation of the Trk receptor tyrosine kinase family (TrkA, TrkB and TrkC) and several members of the TNF receptor superfamily ( $p 75^{\text {NTR }}$, Fas, p55 and p75 TNF receptors). The preferred ligand specificities are shown for each receptor. The black box represents the death domain sequence.

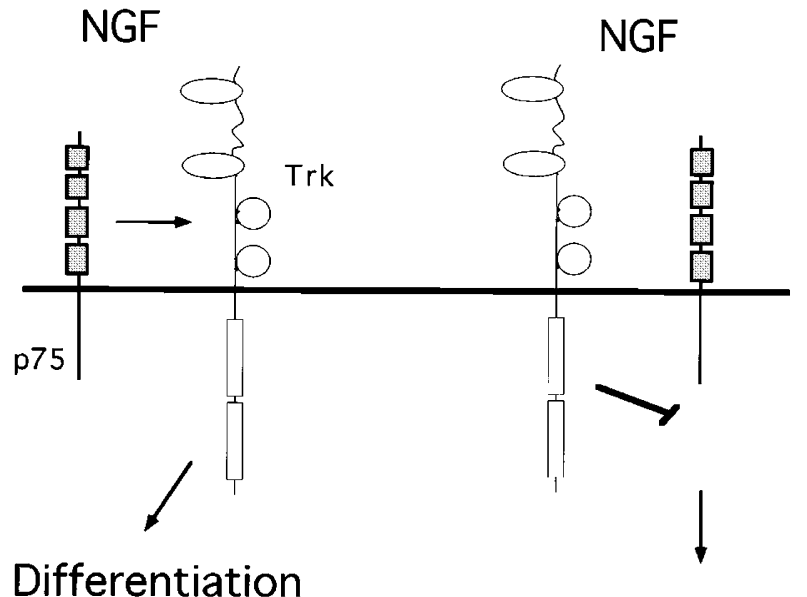

\section{Survival}

Apoptosis

Figure 2 Dual actions of neurotrophins. The effect of NGF in p75 and Trk coexpressing cells is enhanced during cell differentiation and cell survival (left panel). In other cell contexts, p75 overexpression may lead to apoptosis (right panel). TrkA expression and signaling negates p75 death signal. 
1994b). Cell survival is affected by the ratio of the two receptors and the level of NGF provided to neuronal cells. These observations indicate that $\mathrm{p} 75$ can serve as a positive influence upon TrkA function (Figure 2). Alternatively, p75 in these cells may mediate an independent survival signal, which may be augmented by increased TrkA signaling.

Expression of p75 results in higher number of high affinity binding sites by increasing the on-rate of NGF to TrkA, as indicated by kinetic binding studies with ${ }^{125} \mathrm{I}$ NGF (Mahadeo et al, 1994). While very low levels of NGF high affinity binding to TrkA $(1-2 \%)$ have been observed (Klein et al, 1991), co-expression of p75 and TrkA gives a much higher percentage (10-30\%) of high affinity binding sites (Hempstead et al, 1991; Mahadeo et al, 1994; Sutter et al, 1979). This enhancement of binding is dependent upon the relative levels of p75 to TrkA receptors. Regulation of high affinity site formation by coexpression of trkA and p75 provides an explanation for how the receptors may cooperate to increase neurotrophin responsiveness during development. On the other hand, each receptor can also signal independently, implying that the actions of neurotrophins on cell death/survival decisions depend upon whether Trk alone, Trk plus p75, or p75 alone are expressed (Figure 2).

\section{2. p75 as a constitutively active pro-apoptotic receptor}

The model of p75 as a constitutive death receptor was originally formulated by Bredesen and his colleagues (Rabizadeh et al, 1993). Based on the observation that immortalized neural cells overexpressing p75 display an enhanced rate of apoptosis in response to serum withdrawal, a mechanism of ligand-independent death was proposed (see also Bredesen et al, 1998, this issue). According to this model, apoptosis promoted by $\mathrm{p} 75$ can be negated after binding to NGF. The correlation between high levels of $p 75$ expression and susceptibility to apoptosis following growth factor withdrawal in PC12 cells supports this mechanism of cell death (Barrett and Georgiou, 1996). Furthermore, down-regulation of p75 expression in neonatal trk $A^{+}$dorsal root sensory neurons, using an antisense strategy, reveals enhanced survival Barrett and Bartlett, 1994).

In addition, fibroblast cells transfected with TrkA and p75 receptor lacking the cytoplasmic domain exhibited a greater survival advantage upon serum starvation than cells expressing TrkA and full length p75 (Hantzopoulos et al, 1994). Although the initial interpretation was that p75 collaborates with TrkA, an alternative explanation is that the cytoplasmic region of p75 contributes a negative effect upon cell viability. Indeed the identification of a 70-80 amino acid motif in p75 analogous to the death domain of the Fas and p55TNF receptor, consolidated the possibility of a cell death function for p75, similar to other family members (Feinstein et al, 1995; Hofmann and Tschopp, 1995).

An alternative approach to address the role of p75 in neuronal apoptosis has been the generation of a transgenic mouse expressing the intracellular domain of the p75 receptor under the control of the $\alpha 1$ tubulin promoter (Majdan et al, 1997). Interestingly these mice exhibit developmental death of several, but not all, neuronal populations expressing the receptor transgene, indicating that additional cell-specific factors may be required for p75dependent apoptosis. Other mice with targeted mutations in the neurotrophins or their receptors will provide more insight into developmental cell death mechanisms promoted by $\mathrm{p} 75$.

The phenotype of the p75 null mice supports a role for p75 in neuronal survival (Davies et al, 1993; Lee et al, $1994 a, b)$ and suggests an apoptotic function as well. Analysis of mice has also revealed a significantly higher number of cholinergic neurons in the basal forebrain in p $75^{-1-}$ mice compared to wild type controls (Van der Zee et al, 1996; Yeo et al, 1997). These observations indicate that the absence of p75 resulted in enhanced survival, similar to the antisense effects observed in postnatal sensory neurons (Barrett and Bartlett, 1994). Expression of p75 in cholinergic neurons appears to affect apoptosis. This result has been contested by other sterological studies which argue that the number of neurons does not differ between wild type and p75deficient animals (Peterson et al, 1997). A potential explanation to reconcile these opposing conclusions may lie in the genetic backgrounds of the mice that have been examined.

Much of the evidence presented here provides support for the hypothesis that p75 participates in the apoptotic process, but the components responsible for signaling remain to be identified. How does a ligand-independent mechanism lead to death? A potential mechanism is that serum or NGF withdrawal from cells may trigger changes in the p75 receptor structure or in its subcellular localization to adopt a 'killer role'. Alternatively, the action of p75 in the absence of ligand binding may be explained by engagement of the cellular death machinery under conditions of overexpression. Although this has not been functionally
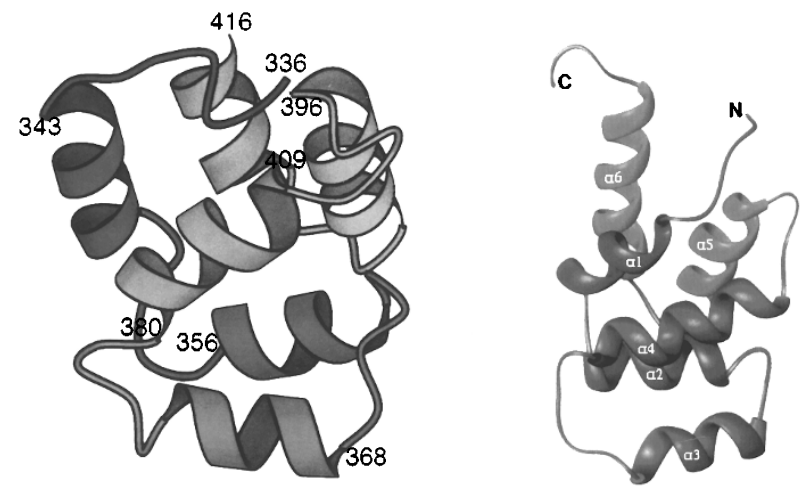

Figure 3 Structural comparison between the C-terminal regions of $p 75$ and Fas receptors. The predicted NMR structure for p75 (Liepinsh et al, 1997) and the Fas death domains (Huang et al, 1996) is shown. The model extends between amino acids 336 and 416 of p75 (left) and between amino acids 202319 of Fas (right). In contrast to Fas and the p55 TNF receptors, the death domain of p75 does not self-associate. 
established, the existence of a death domain sequence located at the C-terminal domain of p75 similar to Fas (see Figure 3) and the p55 TNF receptor suggests the mechanism of apoptosis may be similar. The death domain, a feature of nearly half of the members of the TNF receptor superfamily, functions primarily to provide a docking site for adaptor molecules, such as TNF Receptor Associated Factors (TRAFs), TRADD and FADD. Given the structural similarity between p75 and other TNFR family members, it is conceivable that when p75 is expressed at high levels, apoptosis could result from the interactions of p75 with FADD, TRADD, TRAFs or related proteins in these families.

\section{3. p75 as a ligand-dependent cell death molecule}

After binding to their respective ligands, the Fas and TNF receptors initiate an irreversible set of events culminating in apoptosis. A ligand-dependent mechanism has also been observed with the p75 receptor (Casaccia-Bonnefil et al, 1996b; Frade et al, 1996). Administration of antibodies against NGF or p75 in chick embryos results in the prevention of apoptosis of cells in the dorsal retina at an early developmental age (Frade et al, 1996), indicating that endogenous NGF causes the death of these retinal neurons.

Similarly, in vitro exogenous application of NGF to terminally differentiated primary rat cortical cultures of oligodendrocytes (Casaccia-Bonnefil et al, 1996b) or immortalized smooth muscle cells expressing p75 (Kraemer and Hempstead, personal communication), results in apoptotic death that could be blocked by anti-p75 antibodies. Apoptosis can be detected by fluorescent TUNEL labeling and DNA fragmentation.

Although provocative, the idea that neurotrophins act as potential death-inducing agents is not original, since several in vivo studies had previously indicated that NGF might act as a death inducing agent. Injection of the 192-IgG monoclonal antibody specific for rat p75 (Chandler et al, 1984; Taniuchi and Johnson, 1985) resulted in decreased number of cells in the superior cervical ganglion of embryonic day 16 and newborn rats (Johnson et al, 1989). Although this report has not been widely cited, the implication of these findings is that 192-antibody may act as agonist or may mimick ligand binding to the receptor.

A more direct role for NGF in neuronal apoptosis was suggested by the observation that injection of NGF in newborn rats which had received a facial nerve transection resulted in a $50 \%$ reduction in cell number (Sendtner et al, 1992). Notably, these motor neurons upregulate the levels of p75 upon axotomy (Raivich and Kreutzberg, 1987; Yan and Johnson 1988). Similarly, administration of NGF in chicks produced developmental neuronal cell death of the avian isthmo-optic nucleus, which express high levels of p75 and trkB, but not its cognate receptor, TrkA (von Bartheld et al, 1994).

A perplexing issue raised by these experiments is that although all neurotrophins (NGF, BDNF and NT-3) bind to p75 with similar affinity, each neurotrophin may exert different effects on cell function and viability through p75. For example, the effect of NGF on oligodendrocyte cultures was only observed in a percentage of terminally differentiated cells and could not be reproduced by similar concentrations of BDNF or NT-3. Furthermore, in PC12 cells treated with antisense oligonucleotides to downregulate TrkA expression, BDNF but not NGF can rescue from serum-withdrawal (Taglialatela et al, 1996). A very likely explanation for the effect of distinct neurotrophins in the oligodendrocyte system is the presence of TrkB and TrkC receptors in these cells (Cohen et al, 1996). An alternative explanation, in cells not expressing other Trk receptors, is the differential ability of neurotrophins to activate distinct signal transduction pathways. This hypothesis is also supported by dramatic differences in the kinetics of binding and the degree of positive cooperativity of each neurotrophin to p75 (Rodriguez-Tebar et al, 1990, 1992). An additional explanation may involve different adaptor molecules which are associated with the receptor.

\section{How p75 signals}

Binding of NGF to p75 leads to a wide variety of signals depending on the cell type. In T9 glioma cells, for instance, NGF induces growth arrest (Dobrowsky et al, 1994) while in Schwann cells, it promotes migration (Anton et al, 1994). In mesencephalic neurons, p75 activation results in ceramide production and neurotransmitter release (Blochl and Sirrenberg, 1996); and in melanoma cells, metastasis has been detected as a result of p75 action (Herrmann et al, 1993).

The many functions of p75 cannot simply be explained by a presentation or ligand passing model, particularly in light of evidence indicating that p75 acts independently of trk receptor family members. The ligand-independent and ligand-dependent mechanisms of p75-induced apoptosis may be reconciled in a model that involves activation of the same signaling cascade. For a ligand-independent mechanism, overexpression of the receptor at supraphysiological levels may lead to receptor clustering and oligomerization. Conformational changes may also occur to account for alternative signaling events. Such a change may take place during withdrawal of growth factors or serum. In the ligand-dependent model, binding of dimeric NGF may induce two types of responses: either dissociation of components that constitutively bind to the receptor or recruitment of signalling components analogous to those that associate with members of the TNF receptor superfamily.

A variety of signaling pathways has been suggested for p75. In many cell types, including T9, NIH3T3 and PC12 cells, NGF activation of p75 results in transient elevation of intracellular ceramide levels, due to increased sphingomyelin hydrolysis (Dobrowsky et al, 1994). Treatment with NGF does not induce death in these cell types. In contrast, in NGF-treated oligodendrocytes undergoing apoptosis, ceramide levels are persistently elevated. The NGF effect in oligodendrocytes can be mimicked by the application of exogenous ceramide analogs or bacterial sphingomyelinase or by inhibitors of the glucosylceramide synthase (Casaccia-Bonnefil et al, 1996a). Therefore, the duration of intracellular signaling may explain the differential outcomes of p75 activation in response to NGF. A sustained versus 
transient time course may determine which signaling pathway is dominant.

Alternatively, activation of different enzymatic pathways for ceramide utilization, or localization to specific subcellular compartments, such as caveolae in NIH3T3 or endocytic compartment in axons, maybe distinct in different cell types. In neurons, for instance, p75 has been found at the synaptic terminal, where enzymes responsible for the formation of ceramide-phosphate, such as ceramide kinase have been localized (Bajjalieh et al, 1989; Shinghal et al, 1993). The activation of the enzymatic pathway and the subcellular localization would be consistent with the influence of p75 on dopamine release in mesencephalic neurons (Blochl and Sirrenberg, 1996). Similarly, the localization of p75 to the caveolin compartment in NIH3T3 (Bildenback et al, 1997) would be consistent with the selective signalling properties of the receptor in these cells.

Another hallmark response during apoptosis is the activation of $\mathrm{c}$-jun $\mathrm{N}$-terminal kinase (JNK). This enzyme, an effector of the stress-activated protein kinase cascade, has been implicated in cell death progression of differentiated PC12 cells after NGF withdrawal (Xia et al, 1996). In addition, ceramide is a potential activator of JNK (Verheij et al, 1996). Incubation of mature oligodendrocytes with NGF for $3 \mathrm{~h}$ led to a threefold induction of JNK activation. The induction of JNK activity by NGF is similar in magnitude to the effects of ceramide and is not observed in cells whose viability is not affected by NGF, such as NIH3T3 fibroblasts expressing p75. The activity of the stress-activated protein kinase, JNK, can therefore be upregulated by $\mathrm{p} 75$ under apoptotic conditions.

Ceramide production and JNK activation are also observed in response to TNF treatment of cells. Another common signaling response is the activation of the nuclear transcription factor NF- $\kappa \mathrm{B}$. Correspondingly it has been shown that in primary Schwann cells expressing p75 and not TrkA, NGF activated NF- $k B$ (Carter et al, 1996). This stimulation was not observed by BDNF or NT-3 treatment of Schwann cells, which express TrkB and TrkC, but not TrkA receptors.

When both TrkA and p75 receptors are co-expressed, as in the case of PC12 cells, trkA exerts a suppressive effect upon p75, as assayed by ceramide production (Dobrowsky et al, 1995). In support of this model (Figure 2), introduction of trkA receptors in $\mathrm{PC} 12$ cells results in a reduction of ceramide production stimulated by $\mathrm{p} 75$ binding to NGF. While MAP kinase activity is increased by NGF binding to trkA, JNK activity is suppressed by co-expression of trkA (Yoon, unpublished observations). From these experiments, trkA signaling can selectively negate specific responses from p75 and provide alternative responses to NGF (Figure 2). The impact of trk tyrosine phosphorylation upon p75 suggests that other tyrosine kinase receptors may also interfere with death promoting signals coming from cell death receptors.

Although it is premature to identify the complete biochemical pathway initiated by NGF binding to p75, it is plausible to make certain predictions on potential signaling candidates, given its structural resemblance with other members of the TNF receptor superfamily. A model of the death domain has been proposed based upon an NMR structural analysis (Liepinsh et al, 1997). The cytoplasmic domain is envisioned as a rigid string carrying a globular death domain structure formed by six helices (Figure 3). At the C-terminal end, a potential PDZ binding domain exists for each receptor. Although the overall structure is similar to the Fas death domain, there are several notable differences. The first helix is in a different position for Fas and p75. Additionally, self-association has not been observed with the death domain of p75, in direct contrast to the TNF and Fas receptor sequences. These structural data would predict that, although p75 may interact with common adaptor proteins (such as TRAFs, TRADD, FADD), it may also bind novel signal transduction molecules. Although the death domain of $\mathrm{p} 75$ may associate with the same proteins, the mechanism of recruitment to the membrane may differ from other TNF receptor family members. Alternatively, new proteins in the caspase class, such as I-FLICE/CASH, can prevent cell death by TNF and Fas receptors (Goltsev et al, 1997; Hu et al, 1997) and may provide a means for inhibiting cell death through neurotrophins.

\section{Requirements for an apoptotic signal}

Although there are only few examples in which p75 has been directly shown to be responsible for apoptotic cell death (Table 1), it should be emphasized that many cell types express p75, but do not undergo apoptosis. This suggests that cell context is an important determinant and that p75 alone is not sufficient for this activity. Much effort has been put forth to extrapolate the functions of TNF family members to p75, by assuming that the same actions result from structurally similar receptors. While several signaling mechanisms appear to be shared by NGF and TNF, more experimental work is necessary to understand how neurotrophins stimulate different responses ranging from cell survival to cell suicide. The details for p75 mechanism have been rudimentary and contradictory. A major problem in studying p75 signaling is the lack of suitable cell lines and assays to dissect the contributions of each neurotrophin.

Death induced by NGF is highly dependent on cell type and developmental stage, suggesting that this action requires the cell to be in a specific competent state. Also, the balance between the actions of signaling molecules is crucial to the final life-death decision (Figure 4). In the transgenic mice expressing the truncated cytoplasmic region of $p 75$, the ability of p75 to induce death is highly dependent on the cell type and developmental stage

Table 1 Examples of neurotrophin-related apoptosis

\begin{tabular}{|c|c|}
\hline Cell type & Reference \\
\hline Immortalized neural cell lines & (Rabizadeh et al, 1993) \\
\hline Postnatal sensory neurons & (Barrett and Bartlett, 1994) \\
\hline Chick retina precursors & (Frade et al, 1996) \\
\hline $\begin{array}{l}\text { Basal forebrain cholinergic } \\
\text { neurons }\end{array}$ & (Van der Zee et al, 1996) \\
\hline PC12 cells after NGF withdrawal & (Barrett and Georgiou, 1996) \\
\hline Mature oligodendrocytes & (Casaccia-Bonnefil et al, 1996) \\
\hline Medulloblastoma & ((Muragaki et al, 1997) \\
\hline
\end{tabular}




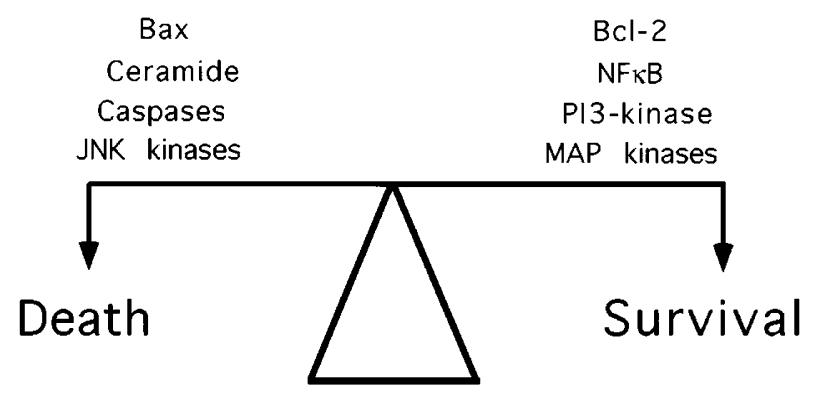

Figure 4 Life and death decisions made by neurotrophins are determined by the balance between the activation and inactivation of specific signaling components, including MAP and JNK enzymes, phosphotidylinositol 3phosphate kinase (PIP3-K), ICE proteases (caspases) and Bcl family members.

(Majdan et al, 1997). Facial motoneurons did not die spontaneously, due to expression of the transgene, but became more sensitive to apoptotic stimuli after nerve injury.

In summary, cell death mediated by p75 is not a generalized phenomenon but, instead, requires specific conditions, with regard to cell type, cell cycle stage, developmental stage, injury or stress.

1. The pro-apoptotic effect of p75 requires the cellular balance between survival/death signals to be significantly shifted towards death (Figure 4). This specific imbalance could be due to age in culture, metabolic impairment, hypoxia, or other types of 'stress' signals, such as nerve injury or trauma. For instance, in the oligodendrocyte model, although in vivo p75 is not expressed in physiological conditions, these cells are highly susceptible to injury and inflammation and may become more reactive to released growth factors and cytokines by upregulating receptor expression at the site of injury. In support of this hypothesis, recent evidence indicates the presence of p75-positive oligodendrocytes in white matter plaques in brain section biopsies obtained from patients with multiple sclerosis (Dowling, unpublished observations).

Similarly, in the chick embryonic retina, not all the cells are susceptible to NGF-induced death through p75. Exogenous administration of NGF in this experimental paradigm does not increase the number of dead cells, suggesting that only cells already predisposed to die by other factors can be killed via a p75-dependent mechanism (Frade et al, 1997).

2. The effect of p75 on cell death is highly dependent on the developmental stage of the cells and by their differentiative state in culture. In the oligodendrocyte lineage, terminally differentiated oligodendrocytes are highly sensitive to NGF-induced death, while O-2A oligodendrocyte progenitors are totally resistent, even if p75 is expressed at high levels using adenoviral vectors (Casaccia-Bonnefil, unpublished observations). Simi- larly, downregulation of p75, using antisense oligonucleotides, results in either decreased or increased survival depending on the developmental stage of DRG neurons (Barrett and Bartlett, 1994). The apoptotic role of p75 has been observed primarily in terminally differentiated cells, while contrasting effects have been observed in undifferentiated cells, such as oligodendrocyte progenitors, medulloblastomas, and tumor cell lines (Cohen et al, 1996; Cortazzo et al, 1996; Muragaki et al, 1997). Although it remains to be demonstrated that p75 signaling affects cell cycle genes, this is an attractive hypothesis that may potentially explain the paradox of p75 being a survival molecule in cultured neuroblastomas (Cortazzo et al, 1996) and apoptotic in primary cultures of post-mitotic cells.

\section{Conclusions}

The contribution of neurotrophins to the welfare of developing neuronal populations is well established. Neurotrophins also mediate other critical functions in the nervous system, including neurotransmitter release, formation of ocular dominance columns in the visual system, and increased synaptic efficacy, as measured by long term potentiation (Thoenen, 1995). Couched behind these activities is the threat of cell elimination. This article indicates that neurotrophins have the capability to kill cells through a pro-apoptotic mechanism, in addition to their ability to prevent a cell suicide pathway.

There are other examples of growth factors and cytokines which carry apoptotic as well as cell survival functions. Bone morphogenetic proteins such as BMP4 can influence early developmental events by inducing apoptosis (Graham et al, 1994) and LIF can cause sympathetic neuron cell death in culture (Kessler et al, 1993). The prominent role of cytokines in inducing apoptosis is underscored by TNF and Fas receptors. TNF's cytotoxic action extends to oligodendrocytes (Louis et al, 1993).

Crosstalk mechanisms between different receptor systems may account for how extracellular factors might exert a fatal as well as a beneficial outcome. Cytokines and growth factors can influence signaling events through other unrelated receptors. For example, TNF- $\alpha$ inhibits insulin signal transduction and elevated levels of TNF are directly correlated with insulin resistance and obesity (Hotamisligil and Spiegelman, 1994). The molecular basis of TNF- $\alpha$ inhibition of insulin action occurs by decreasing the tyrosine phosphorylation of the insulin receptor (Hotamisligil et al, 1994a,b) and its substrate, insulin receptor substrate-1 (IRS-1), a docking protein containing $\mathrm{SH} 2$ domains.

Growing evidence has established a family of transmembrane receptors that serve as mediators of cell death. The pathways leading from death receptor activation and execution of an apoptotic program have quickly become understood at a molecular level. For neurotrophins, their primary function in sustaining the viability of neurons is counterbalanced by a receptor mechanism to eliminate cells by an apoptotic mechanism. It is conceivable that this bidirectional system may be utilized selectively during development and in neurodegenerative diseases. 


\section{References}

Anton ES, Weskamp G, Reichardt LF and Matthew WD (1994) Nerve growth factor and its low affinity receptor promote Schwann cell migration. Proc. Natl. Acad. Sci USA 91: 2795-2799

Bajjalieh SM, Martin TFJ and Floor E (1989) Synaptic vesicle ceramide kinase. J. Biol. Chem. 264: $14354-14360$

Barker PA and Shooter EM (1994) Disruption of NGF binding to the low-affinity neurotrophin receptor $\mathrm{p} 75$ reduces NGF binding to trkA on PC12 cells. Neuron 13: $203-215$

Barrett GL and Bartlett PF (1994) The p75 receptor mediates survival or death depending on the stage of sensory neuron development. Proc. Natl. Acad. Sci. USA 91: 6501-6505

Barrett GL and Georgiou A (1996) The low affinity nerve growth factor receptor p75 mediates death of PC12 cells after nerve growth factor withdrawal. J. Neurosci. Res. 45: 117-128

Bildenback TR, Grigsby RJ and Dobrowsky RT (1997) Association of p75 ${ }^{\mathrm{NTR}}$ with caveolin and localization of neurotrophin-induced sphingomyelin hydrolysis to caveolae. J. Biol. Chem. 272: 10922-10927

Blochl A and Sirrenberg C (1996) Neurotrophins stimulate the release of dopamine from rat mesencephalic neurons via Trk and p75 receptors. J. Biol. Chem. 271: 21100-21107

Bredesen DE and Rabizadeh S (1997) p75NTR and apoptosis: Trk-dependent and Trk-independent effects. TINS 20: 287-291

Bredesen DE, Ye X, Tasinato A, Sperandio S, Assa-Munt N, Rabizadeh S (1998) p $75^{\text {NTR }}$ and the concept of celluar dependence: Seeing how the other half die. Cell Death Differ. 5:

Brojatsch J, Naughton J, Rolls MM, Zingler K and Young JAT (1996) CAR1, a TNFRrelated protein is a cellular receptor for cytopathic avian leukosis-sarcoma viruses and mediates apoptosis. Cell $87: 845-855$

Carter BD and Lewin GR (1997) Neurotrophins live or let die: Does p $75^{\text {NTR }}$ decide? Neuron 18: 187-190

Carter BD, Kaltschmidt C, Kaltschmidt B, Offenhauser N, Bohm-Matthaei R, Baeuerle PA and Barde Y-A (1996) Selective activation of NK-kB by nerve growth factor through the neurotrophin receptor p75. Science 272: 542-545

Casaccia-Bonnefil P, Aibel L and Chao MV (1996a) Central glial and neuronal populations display differential sensitivity to ceramide-dependent cell death. J. Neurosci. Res. 43: 382-389

Casaccia-Bonnefil P, Carter BD, Dobrowsky RT and Chao MV (1996b) Death of oligodendrocytes mediated by the interaction of nerve growth factor with its receptor p75. Nature 383: 716-719

ChandlerCE, Parsons LM, Hosang Mand Shooter EM (1984) A monoclonal antibody modulates the interaction of nerve growth factor with PC12 cells. J. Biol. Chem. 259: $6882-6889$

Chao MV (1992) Neurotrophin receptors: A window into neuronal differentiation. Neuron 9: 583-593

Chao MV and Hempstead BL (1995) p75 and trk: A two receptor system. Trends in Neuroscience 19: 321-326

Chinnaiyan AM, O'Rourke K, Yu G-L, Lyons RH, Garg M, Duan DR, Xing L, Gentz R, $\mathrm{Ni}$ J and Dixit VM (1996) Signal transduction by DR3, a death domain-containing receptor related to TNFR-1 and CD95. Science 274: 990-992

Cohen RI, Marmur R, Norton WT, Mehler MF and Kessler JA (1996) Nerve growth factor and neurotrophin-3 differentially regulate the proliferation and survival of developing rat brain oligodendrocytes. J. Neurosci. 16: 6433-6442

Cortazzo MH, Kassis ES, Sproul KA, Schor NF (1996) Nerve growth factor (NGF)mediated protection of neural crest cells from antimitotic agent-induced apoptosis: The role of the low-affinity NGF receptor. J. Neurosci. 16:3895-3899

Davies A, Lee K-F and Jaenisch R (1993) p75 deficient trigeminal sensory neurons have an altered response to NGF but not to other neurotrophins. Neuron 11: 120

Dobrowsky RT, Jenkins GM and Hannun YA (1995) Neurotrophins induce sphingomyelin hydrolysis. J. Biol. Chem. 270: 22135-22142

Dobrowsky RT, Werner MH, Castellino AM, Chao MV and Hannun YA (1994) Activation of the sphingomyelin cycle through the low-affinity neurotrophin receptor. Science 265: 1596-1599

Fainzilber M, Smit AB, Syed NI, Wildering WC, Hermann PM, van der Schors RC, Jimenez C, Li KW, van Minnen J, Bulloch AGM, Ibanez CF and Geraerts WPM (1996) CRNF, a molluscan neurotrophic factor I that interacts with the p75 neurotrophin receptor. Science 274: 1540-1543
Feinstein E, Kimchi A, Wallach D, Boldin M and Varfolomeev E (1995) The death domain: a module shared by proteins with diverse cellular functions. TIBS 20: $342-344$

Frade JM, Rodriguez-Tebar A and Barde Y-A (1996) Induction of cell death by endogenous nerve growth factor through its p75 receptor. Nature 383: 166168

Frade JM, Bovolenta P, Martinez-Morales JR, Arribas A, Barbas JA, RodriguezTebar A (1997) Control of early cell death by BDNF in the chick retina. Development 124: 3313-3320.

Goltsev YV, Kovalenko AV, Arnold E, Varfolomeev EE, Brodianskii VM and Wallach D (1997) CASH, a novel caspase homologue with death effector domains. J. Biol. Chem. 272: 19641-19644

Graham A, Francis-West P, Brickell P and Lumsden A (1994) The signaling molecule BMP4 mediates apoptosis in the rhombencephalic neural crest. Nature 372: $684-686$

Greene LA and Shooter EM (1980) The nerve growth factor: biochemistry, synthesis and mechanism of action. Ann. Rev. Neurosci. 3: 353-402

Hantzopoulos PA, Suri C, Glass DJ, Goldfarb MP and Yancopoulos GD (1994) The low affinity NGF receptor, p75, can collaborate with each of the Trks to potentiate functional responses to the neurotrophins. Neuron 13: 187-207

Hempstead BL, Martin-Zanca D, Kaplan DR, Parada LF and Chao MV (1991) Highaffinity NGF binding requires co-expression of the trk proto-oncogene and the low-affinity NGF receptor. Nature 350: 678-683

Herrmann JL, MenterDG, Hamada J, Marchetti D, Nakajima Mand Nicolson G (1993) Mediation of NGF-stimulated extracellular matrix invasion by the human melanoma p75 neurotrophin receptor: p75 functions independently of trkA. Mol. Biol. Cell 4: 1205-1216

Hofmann K and Tschopp J (1995) The death domain motif found in Fas (Apo-1) and TNF receptor is present in proteins involved in apoptosis and axonal guidance. FEBS Letters 371: $321-323$

Hotamisligil GS and Spiegelman BM (1994) Tumor necrosis factor $\alpha$ : A key component of the obesity-diabetes link. Diabetes 43: 1271-1278

Hotamisligil GS, Budavari A, Murray D and Spiegelman BM (1994a) Reduced tyrosine kinase activity of the insulin receptor in obesity-diabetes. J. Clin. Invest. 94: $1543-1549$

Hotamisligil GS, Murray DL, Choy LN and Spiegelman BM (1994b) Tumor necrosis factor a inhibits signaling from the insulin receptor. Proc. Natl. Acad. Sci. USA 91: $4854-4858$

Hu S, Vincenz C, Ni J, Gentz R and Dixit VM (1997) I-FLICE, a novel inhibitor of tumor necrosis factor receptor-1 and CD95-induced apoptosis. J Biol Chem 272: $17255-17257$

Huang BH, Eberstadt M, Olejniczak ET, Meadows RP and Fesik SW (1996) NMR structure and mutagenesis of the Fas (Apo-1/CD95) death domain. Nature 384: $638-641$

Johnson EM, Osborne PA and Taniuchi M (1989) Destruction of sympathetic and sensory neurons in the developing rat by a monoclonal antibody against the nerve growth factor (NGF) receptor. Brain Res. 478: 166-170

Kessler JA, Ludlam WH, Freidin MM, Hall DH, Michaelson MD, Spray DC, Dougherty M and Batter DK (1993) Cytokine-induced programmed death of cultured sympathetic neurons. Neuron 11: 1123-1132

Klein R, Jing S, Nanduri V, O'Rourke E and Barbacid M (1991) The trk tyrosine protooncogene encodes a receptor for nerve growth factor. Cell 65: 189-197

Lee K-F, Bachman K, Landis S and Jaenisch R (1994a) Dependence on p75 for innervation of some sympathetic targets. Science 263: 1447-1449

Lee K-F, Davies A and Jaenisch R (1994b) p75-deficient embryonic dorsal root sensory and neonatal sympathetic neurons display a decreased sensitivity to NGF. Development 120: 1027-1033

Lee K-F, Li E, Huber LJ, Landis SC, Sharpe AH, Chao MV and Jaenisch R (1992) Targeted mutation of the gene encoding the low affinity NGF receptor p 75 leads to deficits in the peripheral nervous system. Cell 69: 737-749

Liepinsh E, Ilag LL, Otting G, Ibanez CF (1997) NMR structure of the death domain of the p75 neurotrophin receptor. EMBO J. 16: 4999-5005

Louis JC, Magal E, Takayama S and Varon S (1993) CNTF protection of oligodendrocytes against natural and tumor necrosis factor-induced death. Science 259: 689-692

Mahadeo D, Kaplan L, Chao MV and Hempstead BL (1994) High affinity nerve growth factor binding displays a faster rate of association than p140(trk) bindingimplications for multisubunit polypeptide receptors. J Biol Chem 269: 68846891 
Majdan M, Lachance C, Gloster A, Aloyz R, Zeindler C, Bamji S, Bhakar A, Belliveau D, Fawcett J, Miller FD and Barker PA (1997) Transgenic mice expressing the intracellular domain of the $p 75$ neurotrophin receptor undergo neuronal apoptosis. J. Neurosci 17: 6988-6998

Montgomery RI, Warner MS, Lum BJ and Spear PG (1996) Herpes simplex virus-1 entry into cells mediated by a novel member of the TNF/NGF receptor family. Cell 87: $427-436$

Muragaki Y, Chou TT, Kaplan DR, Trojanowski J and Lee V-M (1997) Nerve growth factor induces apoptosis in human medulloblastoma cell lines that express trkA receptors. J. Neurosci. 17: 530-542

Pan G, O'Rourke K, Chinnaiyan AM, Gentz R, Ebner R, Ni J and Dixit VM (1997) The receptor for the cytotoxic ligand TRAIL. Science 276: 111-113

Peterson DA, Leppert JT, Lee K-F and Gage FH (1997) Basal forebrain neuronal loss in mice lacking neurotrophin receptor p75. Science 277: 837-838

Rabizadeh S, Oh J, Zhong LT, Yang J, Bitler CM, Butcher LL and Bredesen DE (1993) Induction of apoptosis by the low-affinity NGF receptor. Science 261: 345-348

Raivich G and Kreutzberg GW (1987) Expression of growth factor receptors in injured nervous tissue. J. Neurocytol. 16: 689-700

Rodriguez-Tebar A, Dechant G and Barde Y-A (1990) Binding of brain-derived neurotrophic factor to the nerve growth factor receptor. Neuron 4: 487-492

Rodriguez-Tebar A, Dechant G, Gotz R and Barde YA (1992) Binding of neurotrophin-3 to its neuronal receptors and interactions with nerve growthfactor and brain-derived neurotrophic factor. EMBO J. 11: 917-922

Ross AH, Kaplan DR and Wolf D (1996) J. Cell Biol. 132: 945-953

Sendtner MB, Holtmann R, Kolbech H, Thoenen H and Barde Y-A (1992) Brainderived neurotrophic factor prevents the death of motoneurons in newborn rats after nerve transection. Nature 360: 757-759

Shinghal R, Scheller RH and Bajjalieh SM (1993) Ceramide 1-phosphate phosphatase activity in brain. J. Neurochem. 61: 2279-2285

Smith CA, Farrah T and Goodwin RG (1994) The TNF receptor superfamily of cellular and viral proteins: Activation, costimulation and death. Cell 76: 959-962

Snider WD (1994) Functions of the neurotrophins during nervous-system development - what the knockouts are teaching us. Cell 77: 627-638
Sutter A, Riopelle RJ, Harris-Warrick RM and Shooter EM (1979) NGF receptors: characterization of two distinct classes of binding sites on chick embryo snesory ganglia cells. J. Biol. Chem. 254: 5972-5982

Taglialatela G, Hibbert CJ, Hutton LA, Werrbach-Perez K and Perez-Polo JR (1996) Suppression of $p 140$ trkA does not abolish nerve growth factor-mediated rescue of serum-free PC12 cells. J. Neurochem. 66: 1826-1835

Taniuchi M and Johnson EM, Jr. (1985) Characterization of the binding properties and retrograde axonal transport of a monoclonal antibody directed against the rat nerve growth factor receptor. J. Cell Biol. 101: 1100-1106

Thoenen H (1995) Neurotrophins and neuronal plasticity. Science 270: 593-598

Van der Zee CEEM, Ross GM, Riopelle RJ and Hagg T (1996) Survival of cholinergic forebrain neurons in developing p75NGFR-deficient mice. Science 274: 17291732

Verdi JM, Birren SJ, Ibanez CF, Persson H, Kaplan DR, Benedetti M, Chao MV and Anderson DJ (1994) p75(LNGFR) regulates trk signal transduction and NGFinduced neuronal differentiation in MAH cells. Neuron 12: 733-745

Verheii M, Bose R, Lin X-H, Yao B, Grant S, Birrer MJ, Szabo E, Zon LI, Kyriakis JM, Haimovitz-Friedman A, Fuks Z and Kolesnick RN (1996) Requirement for ceramide-initiated SAPK/JNK signalling in stress-induced apoptosis. Nature 380: $75-79$

von Bartheld CS, Kinoshita Y, Prevette D, Yin Q-W, Oppenheim RW and Bothwell MA (1994) Positive and negative effects of neurotrophins on the isthmo-optic nucleus in chick embryos. Neuron 12: 639-654

XiaZ, Dickens M, Raingeaud J, Davis RJ and Greenberg ME (1996) Opposing effects of ERK and JNK-p38 MAP kinases on apoptosis induced by neurotrophic factor withdrawal. Science 270: 1326-1331

Yan Q and Johnson EM (1988) An immunohistochemical study of nerve growth factor receptor expression in developing rats. J. Neurosci. 8: 3481-3498

YeoTT, Chua-Couzens J, ButcherLL, Bredesen DE, Cooper JD, Valletta JS, Mobley, WC, Longo, FM (1997) Absence of p75 causes increased basal forebrain cholinergic neuron size, choline acetyltransferase activity, and target innervation. J. Neurosci. 17: 7594-7605. 